\title{
Processo avaliativo do Sistema Nacional de Pós- Graduação: um estudo da percepção de docentes
}

\author{
Juliane Medeiros de Lima \\ Bacharel em Biblioteconomia pela Universidade Federal do \\ Rio Grande do Norte (UFRN) \\ E-mail: julianeml83@gmail.com \\ Nadia Aurora Vanti Vitulo \\ Doutora em Informação e Comunicação pela Universidade Federal do Rio Grande do Sul \\ Professora Adjunta do Departamento de Ciência da Informação da UFRN \\ E-mail: nvanti@ufrnet.br
}

\begin{abstract}
RESUMO:
O presente estudo é resultado de pesquisa realizada com os docentes permanentes credenciados aos Programas de Pós-Graduação do Centro de Ciências Sociais Aplicadas (CCSA) da Universidade Federal do Rio Grande do Norte (UFRN), objetivando avaliar a percepção dos mesmos acerca do processo avaliativo do Sistema Nacional de Pós-Graduação (SNPG), no que se refere à avaliação da produção científica docente. A coleta de dados foi realizada por meio de questionário, com perguntas abertas e fechadas, enviado eletronicamente a todos os professores permanentes dos PPGs do CCSA/UFRN. Como resultado, apresentaram-se os diversos pontos de vista dos participantes da pesquisa, bem como críticas e sugestões de melhorias ao referido sistema de avaliação.
\end{abstract}

Palavras chave: Avaliação Capes. Produção científica. Sistema Nacional de PósGraduação.

\begin{abstract}
:
The current study is a result of a research performed with the permanent professors accredited to the Graduate Programs of the Center of Applied Social Sciences (CCSA) of the Federal University of Rio Grande do Norte (UFRN), objectifying the perception of the same about the evaluation process of the National Postgraduate System (SNPG), with regard to evaluation of teacher scientific production. Data collection was done through a questionnaire, with open and closed questions, sent electronically to all the permanent teachers of the PPGs of the CCSA/UFRN. As a result, the various points of view of the research participants were presented, as well as criticisms and suggestions for improvements to the evaluation system mencioned.
\end{abstract}

Keywords: Capes Evaluation. Scientific production. National Postgraduate System. 


\section{INTRODUÇÃO}

No Brasil, assim como na maioria dos países, há um grande investimento, por parte do Estado, em pesquisas científicas, tanto na disponibilização de auxílio financeiro para projetos de pesquisa, como em concessão de bolsas para pesquisadores. Todo investimento visa a um retorno. Nesse caso em particular, o Estado investe em pesquisas que terão resultados publicados, em forma de comunicação científica, dando retorno à sociedade, que por sua vez, por meio de apropriação dos novos conhecimentos geram mais pesquisas científicas.

A Capes é também o órgão responsável pelo processo avaliativo do Sistema Nacional de Pós-Graduação (SNPG). A avaliação é realizada a cada quadriênio, entretanto, anualmente as informações sobre o Programa de Pós-Graduação são inseridas através do sistema de coleta de dados da Instituição. Os critérios adotados para avaliação são: proposta do programa; corpo discente; corpo docente, produção intelectual; inserção social.

O quesito produção intelectual docente é preocupação constante e central nos Programas de Pós-Graduação em geral, pois as publicações qualificadas do Programa, por docente permanente, é um dos pontos de maior peso na avaliação da Capes. Em consequência disso, os docentes credenciados aos PPGs, são permanentemente cobrados a publicar suas pesquisas em periódicos qualificados, para consecução de pontuação mínima que permita ao Programa ser avaliado de maneira satisfatória à permanência ou evolução do conceito atribuído pela Capes em avaliação anterior.

A corrida docente para o alcance desta pontuação acaba por gerar um produtivismo acadêmico, pois privilegia o quantitativo em detrimento ao qualitativo. Estimula a criação de variações sobre um mesmo tema, proporcionando a publicação de uma mesma pesquisa em diferentes periódicos, apresentando apenas poucas alterações. O tempo para o qual o professor/pesquisador dedica a sua pesquisa é reduzido, em virtude da pontuação que deve ser alcançada em um período de tempo determinado.

Face ao exposto, o trabalho se propôs a investigar a percepção dos professores que estão imersos nessa realidade, acerca do processo avaliativo do SNPG, no que concerne à produção científica docente, por meio de estudo de caso realizado com os 
docentes permanentes credenciados aos Programas de Pós-Graduação do Centro de Ciências Sociais Aplicadas da Universidade Federal do Rio Grande do Norte.

O objetivo geral do estudo é avaliar a percepção dos professores do Centro de Ciências Sociais Aplicadas (CCSA), credenciados como docentes permanentes aos Programas de Pós-Graduação do referido Centro, a respeito das métricas de avaliação da produção científica utilizadas pelo SNPG, partindo da seguinte pergunta problema: Qual a percepção dos professores permanentes credenciados aos Programas de PósGraduação do CCSA/UFRN acerca do processo avaliativo do SNPG, no que concerne à produção científica docente?

Especificamente, a pesquisa objetivou, com base em levantamento bibliográfico a respeito do que se tem produzido sobre o tema, descrever o processo de avaliação do SNPG, realizado pela Capes e refletir sobre a adaptação dos docentes de pós-graduação ao produtivismo acadêmico, resultante desse processo.

\section{PROCESSO AVALIATIVO DO SISTEMA NACIONAL DE PÓS-GRADUAÇÃO}

A história da avaliação da educação superior no Brasil teve início durante o regime militar, por meio da avaliação dos cursos de pós-graduação, objetivando o desenvolvimento científico e tecnológico do país (BERTOLIN, 2004). No Brasil, a qualificação de pesquisadores foi incentivada a partir da década de 60 , época em que o ensino superior passou por reorganização e rápida expansão. A pós-graduação brasileira foi criada com a função social de qualificar recursos humanos e produzir conhecimento científico e tecnológico para expansão industrial do país. O Sistema Nacional de PósGraduação foi organizado sendo "parte de um esforço mais amplo de impulsionar o desenvolvimento do país" (MOREIRA; VELHO, 2008, p. 632).

O processo avaliativo do SNPG é de responsabilidade da Coordenação de Aperfeiçoamento de Pessoal de Nível Superior (CAPES) e orientado pela Diretoria de Avaliação desta instituição. A Capes, para recomendar, reconhecer e atribuir conceitos aos cursos de pós-graduação, utiliza-se do sistema de avaliação por pares (peer review), onde apenas os próprios cientistas podem avaliar o trabalho de outros pesquisadores. $A$ revisão por pares decide pela relevância e seleção da pesquisa, publicação acadêmica, seleção e promoção de cientistas e investimentos institucionais As críticas apontadas a 
esse sistema apontam para o seu caráter "corporativista" e de "universo fechado", na medida em que não sai do universo dos "atores tradicionais da ciência" (MOREIRA; VELHO, 2008, p. 638).

Nos primeiros anos da década de 1950, quando a Capes foi criada, sua prioridade "era apoiar a formação de professores, no Brasil ou no exterior, para atuação no ensino superior, especialmente nas universidades públicas" (BIANCHETTI; VALLE, 2014, p. 90). Em 1976, a Capes “organizou o primeiro processo de avaliação dos programas de pósgraduação, centrando sua avaliação da produção científica dos pesquisadores ligados a cada programa" (BALBACHEVSKY, 2005 apud ALVES; MARICATO; MARTINS, 2015, p. 153). Com a queda da ditadura e recuperação da democracia, já em meados dos anos de 1990, os Programas de Pós-Graduação sofreram mudanças na sua forma de avaliação, gestão e financiamento, que afetaram os pesquisadores, bem como, a qualidade da produção de conhecimento. A mudança nos objetivos da Capes, de formação de professores para o ensino superior à formação de pesquisadores foi uma das modificações que influenciaram em grande parte a avaliação dos PPGs (BIANCHETTI; VALLE, 2014).

A Avaliação, na forma como foi estabelecida a partir de 1998, pretende assegurar e manter a qualidade dos cursos de mestrado e doutorado em todo o país, sendo base para distribuição de recursos financeiros para apoio às pesquisas, na forma de financiamentos de projetos, bolsas de estudo, dentre outros (CAPES, 2014).

O Sistema de Avaliação divide-se em dois processos distintos que se referem à entrada (criação de novos cursos) e à permanência (avaliação quadrienal) dos cursos de mestrado profissional, mestrado e doutorado acadêmicos no SNPG (CAPES, 2014).

A partir do ano de 2015 a avaliação dos Programas de Pós-Graduação deixou de ser realizada trienalmente, passando a ser feita a cada quatro anos. Entretanto, há um acompanhamento anual dos cursos, realizado por meio de sistema de informação automatizado, a Plataforma Sucupira, onde são inseridos dados predominantemente quantitativos sobre os cursos de mestrado e doutorado dos PPGs.

Ao final do processo avaliativo, referente ao quadriênio, é atribuído ao Programa um conceito que varia entre 1 e 7. Os PPGs que recebem conceitos 1 e 2 são descredenciados e passam a não ter mais reconhecimento do Ministério da Educação. $\mathrm{O}$ conceito 3 indica que o Programa apresenta desempenho regular, enquanto que o 4 
apresenta desempenho bom, e o conceito 5 é o maior atribuído a Programas que funcionam apenas com o curso de mestrado. Por fim, os conceitos 6 e 7 são atribuídos a PPGs com padrões de excelência internacional (CAPES, 2013).

Apesar de eminentemente quantitativo, o sistema de avaliação da Capes também possibilita inserção de dados qualitativos. A avaliação é composta por cinco dimensões, a saber: proposta do programa; corpo docente; corpo discente, teses e dissertações; produção intelectual; inserção social. Os pesos dos quesitos e a inclusão de novos itens nas fichas de avaliação estão definidos nos documentos de área de cada Programa especificamente. De todas as dimensões, a única avaliada quanto a critérios qualitativos é a proposta do programa. (CAPES, 2013).

A avaliação da dimensão "produção intelectual" tem por base as pontuações adquiridas pelos docentes, somadas durante o quadriênio, ao publicarem artigos científicos em periódicos qualificados pelo sistema qualis-periódicos. Em consequência disso, os professores permanentes dos PPGs são cobrados a produzirem o suficiente para que o Programa receba uma nota satisfatória na avaliação do SNPG, desencadeando o que se pode chamar de produtivismo acadêmico.

Segundo Moreira e Velho (2008, p. 635-636), a Capes

utiliza critérios de avaliação que levam ao aumento na disputa dos cursos por mais recursos, associada à obtenção dos melhores conceitos. Isso obriga os membros da comunidade científica a demonstrar cada vez mais produtividade científica, sobretudo, em termos de publicação nos veículos acadêmicos de melhor reputação nos respectivos campos [...] gerando uma luta constante do pesquisador pela superação de seus próprios desempenhos no que diz respeito ao número de trabalhos que publica.

O processo avaliativo do SNPG é alvo de diversas discussões e críticas acadêmicas. Muitos estudos foram realizados a respeito do tema. Horta (2006) publicou um artigo onde foram utilizadas como fontes primárias da pesquisa, críticas e sugestões, encaminhadas à Capes, feitas pelos coordenadores de PPGs de todas as áreas, na coleta de dados realizada pela instituição, referente ao ano de 2004. As mesmas foram agrupadas e resumidas pelo autor em cinco blocos: críticas ao caráter homogeneizador do modelo; críticas ao quantitativismo e produtivismo; críticas à ausência de indicadores do alcance social das atividades dos Programas e propostas de introdução dos mesmos; inserção internacional; e, consequências da avaliação. 
Moreira e Velho (2008), argumentam que as políticas de gestão da PósGraduação não devem ser embasadas apenas em critérios acadêmicos para avaliar os cursos e a produção do conhecimento. Acreditam que o contexto de aplicação prática do conhecimento deve ser considerado na avaliação, de modo a incentivar a formação de recursos humanos (aptos a trabalhar em diferentes ambientes, não apenas acadêmico) e a produção do conhecimento relevante para a sociedade.

Souza (2014) acredita que os sistemas de avaliação de pesquisadores e programas de pós-graduação, utilizados pelo CNPq e Capes, têm transformado "docentes e alunos em burocráticos produtores de artigos, afastando-os dos reais problemas da ciência e da sociedade, bem como da busca por conhecimentos e pensamentos realmente novos" (SOUZA, 2014, p. 2)

A ênfase dada, pelo modelo avaliativo do Sistema Nacional de Pós-Graduação, aos indicadores quantitativos e à produção bibliográfica promove uma política centrada na produtividade, trazendo consequências diversas a nível individual e coletivo. $O$ produtivismo acadêmico surge em decorrência da avaliação do SNPG.

\section{METODOLOGIA}

O método de abordagem utilizado para a realização da pesquisa foi o método indutivo, pois partiu da observação de um grupo ou amostra, para estabelecer uma generalização ao todo. No caso específico, os sujeitos da pesquisa foram os docentes permanentes vinculados aos PPGs do CCSA, que foram questionados a respeito dos métodos de avaliação utilizados pela Capes para atribuição do conceito dos Programas. A partir dessa amostra, é possível estender os resultados aos demais docentes de PPGs, os quais estão inseridos em condição de avaliação similar.

A respeito do método utilizado, descreve Lakatos e Marconi (2003, p. 86): a "indução é um processo mental por intermédio do qual, partindo de dados particulares, suficientemente constatados, infere-se uma verdade geral ou universal, não contida nas partes examinadas".

Com relação ao procedimento, utilizou-se o método monográfico, que se justificou pela realização de um estudo de caso com os docentes credenciados a Programas de Pós-Graduação do CCSA/UFRN, partindo do princípio de que "qualquer 
caso que se estude em profundidade pode ser considerado representativo de muitos outros ou até de todos os casos semelhantes" (LAKATOS; MARCONI, 2003, p. 108).

Severino (2007, p 121), corroborando com Lakatos e Marconi (2003), define estudo de caso por "pesquisa que se concentra no estudo de um caso particular, considerado representativo de um conjunto de casos análogos, por ele significativamente representativo".

A primeira parte da pesquisa foi realizada através de fontes secundárias, por meio de estudo predominantemente bibliográfico, com base em teóricos clássicos, como também, em pesquisadores da atualidade, por meio de livros, artigos e publicações pertinentes sobre o tema. Segundo Rampazzo (2002, p. 53), "a pesquisa bibliográfica procura explicar um problema a partir de referências teóricas publicadas (em livros, revistas, etc.). Pode ser realizada independentemente, ou como parte de outros tipos de pesquisa".

Em seguida, teve início a pesquisa de campo, que, como segundo passo, permitiu o estabelecimento de "um modelo teórico inicial de referência", da mesma forma que contribuiu na "determinação das variáveis e elaboração do plano geral da pesquisa" (LAKATOS; MARCONI, 2003, p. 186). A pesquisa de campo foi do tipo quantitativodescritiva. Conforme definição de Tripodi (1975), citado por Lakatos e Marconi (2003, p. 187), estudos quantitativo-descritivos,

[..] empregam artifícios quantitativos tendo por objetivo a coleta sistemática de dados sobre populações, programas, ou amostras de populações e programas. Utilizam várias técnicas como entrevistas, questionários, formulários etc. e empregam procedimentos de amostragem.

A técnica utilizada foi a observação direta extensiva, por meio de aplicação de questionários, aplicados através da web (online) com perguntas abertas, fechadas e de múltipla escolha.

A justificativa da escolha de pesquisa bibliográfica, de campo e com aplicação de questionário se deveu à pretensão de estudar o tema com base no estado da arte já existente, como também na opinião dos sujeitos envolvidos na pesquisa, de forma que a pergunta problema fosse respondida de maneira satisfatória. 
A pretensão da pesquisa foi conseguir o maior número de opiniões a respeito do sistema avaliativo da Capes, no que tange a produção e publicação de artigos científicos, dos sujeitos que estão diretamente envolvidos nesse processo: os docentes permanentes dos PPGs. Para tal fim, levantou-se o número de docentes permanentes dos programas do Centro de Ciências Sociais Aplicadas da UFRN e foi enviado a todos, através de email, o questionário com perguntas abertas e fechadas, conforme descrito na anteriormente na metodologia.

Ao todo o CCSA/UFRN possui oito PPGs: administração, ciências contábeis, direito, economia, gestão da informação e do conhecimento, gestão pública, serviço social e turismo. O total de docentes permanentes dos oito PPGs do Centro somam ao todo 93 professores. O questionário foi enviado eletronicamente para todos eles e reenviado alguns meses depois, obtendo-se ao final 19 respostas. Desse modo, serão apresentadas, como resultados da pesquisa, apenas as análises dos questionários respondidos.

O questionário foi composto por 14 questões, das quais 12 eram perguntas fechadas e duas abertas. As três primeiras questões referiam-se ao diagnóstico do docente em relação ao programa ou programas nos quais atuam, tais como tempo de permanência no PPG atual ou em PPGs, no geral, dentre outras. As demais questões foram voltadas à prática do docente no programa de pós-graduação, no que tange a exigências, prazos, estratégias para publicação, cobranças do PPG, metas a cumprir, etc. Diante da possibilidade de um mesmo docente atuar em dois ou mais PPGs, trabalhouse com foco no programa em que o professor atuava há mais tempo.

\section{RESULTADOS}

Conforme dito anteriormente, o questionário foi enviado eletronicamente a todos os docentes permanentes do CCSA, e obteve-se aproximadamente $20 \%$ de retorno. O gráfico 1 apresenta a quantidade de professores respondentes por Programa. 
Gráfico 1 - PPGs pertencentes ao CCSA

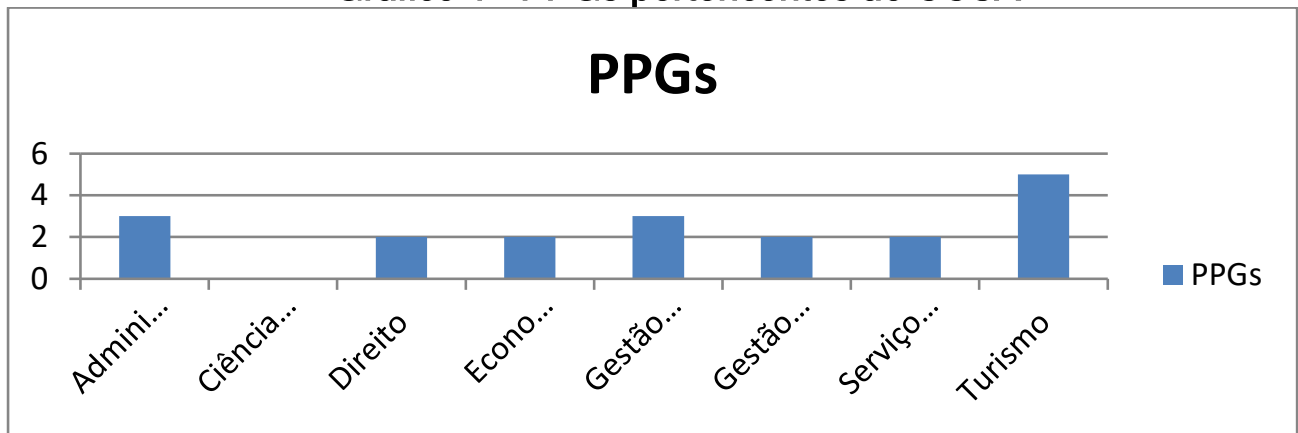

Fonte: Produção da autora.

Nas perguntas com finalidade de diagnóstico, questionou-se a quantidade de tempo de atuação do docente em Programas de Pós-Graduação, a fim de investigar o tempo em que o professor estava inserido no contexto de docente permanente de pósgraduação e, consequentemente, em contato com as normas do sistema avaliativo do SNPG. Conforme apresenta o gráfico 2, mais de 50\% dos docentes respondentes estavam credenciados a programas de pós-graduação há mais de sete anos. Outro percentual considerável $(41,2 \%)$ atuava há mais de um ano e menos de quatro anos. Não houve respostas em que a permanência no PPG fosse de até um ano. Isso implica dizer que todos os entrevistados já passaram por, pelo menos, uma avaliação anual do SNPG.

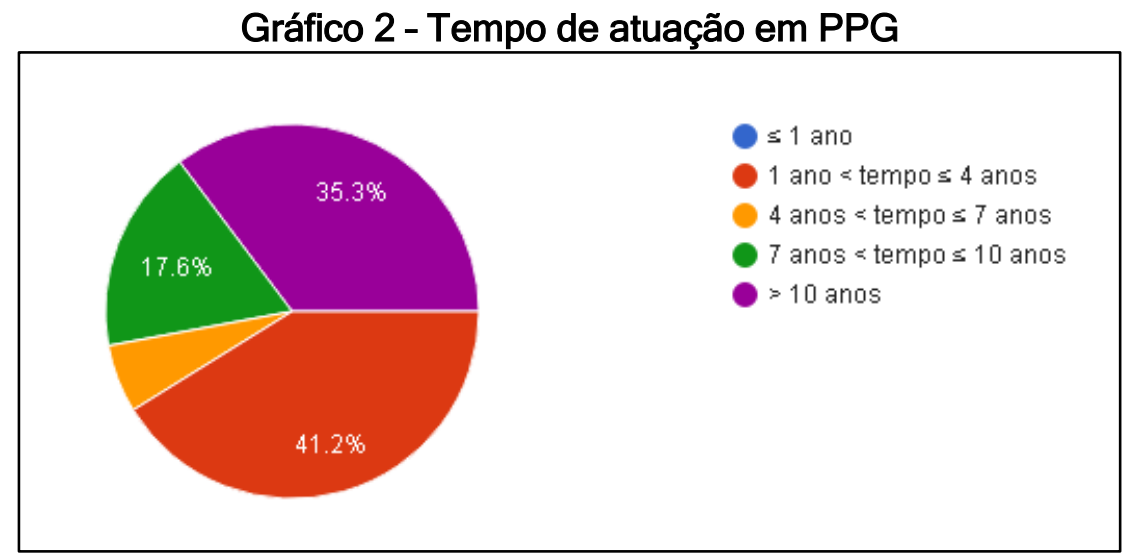

Fonte: Produção da autora.

Dando continuidade à pesquisa, apresentaram-se perguntas de cunho procedimental, com relação a como o PPG trabalhava internamente com seu corpo docente para adaptar-se e responder de forma satisfatória aos critérios estipulados pelo sistema avaliativo do SNPG. As questões realizadas para este fim foram: "Com que 
frequência a coordenação do PPG cobra publicações em periódicos qualificados pela CAPES?"; "Quantos pontos são necessários para que cada docente atinja a meta estipulada pelo PPG, durante o quadriênio?".

O gráfico 3 mostra que $44,4 \%$ dos Programas costumam cobrar as publicações dos docentes anualmente. Isto pode ser justificado pelo fato da Capes solicitar informações aos cursos, por meio da Plataforma Sucupira, anualmente, ainda que a avaliação direcionada à emissão do conceito do PPG seja realizada a cada quatro anos.

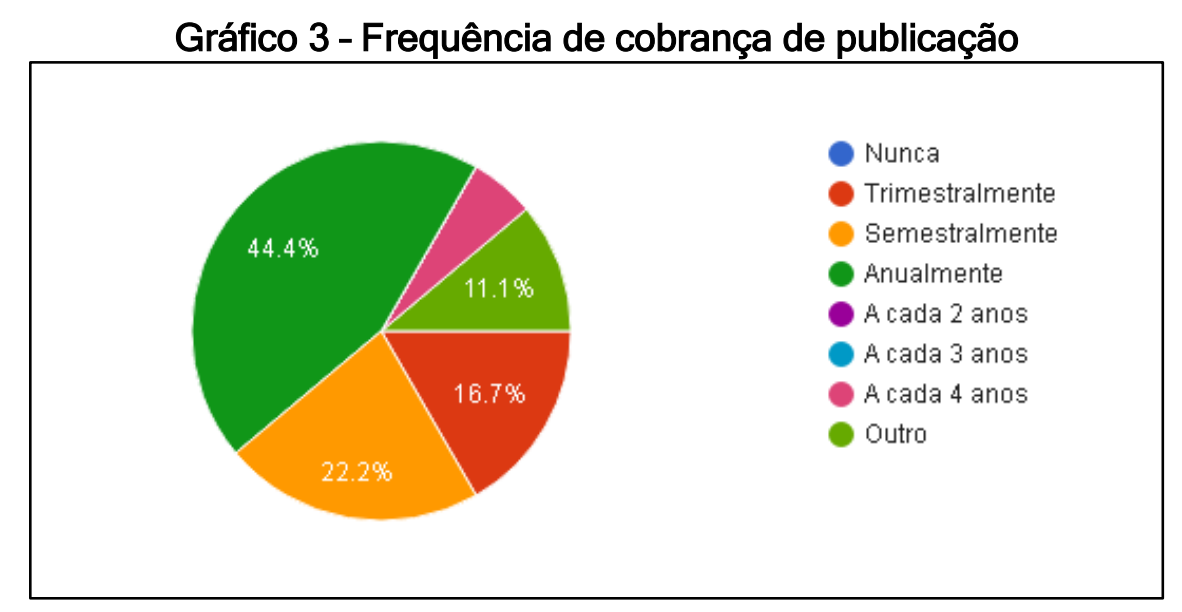

Fonte: Produção da autora.

No gráfico 4 é apresentada a pontuação mínima necessária para que o professor permaneça na qualidade de docente permanente do Programa. Essa pontuação varia de acordo com o conceito do PPG, se existe apenas o curso de mestrado ou se há a existência de mestrado e doutorado, dentre outros motivos.

Gráfico 4 - Pontuação exigida pelos PPGs 


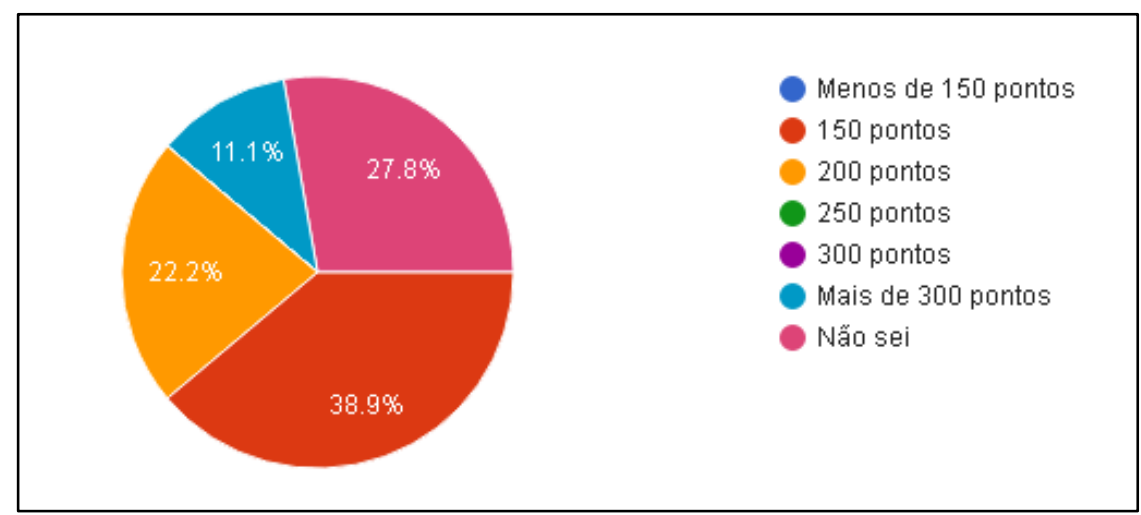

Fonte: Produção da autora.

Quanto maior o conceito, maior deve ser a pontuação dos docentes. Para um Programa manter, por exemplo, um conceito 4 (bom), voltando apenas para o quesito produção docente, cada docente deverá apresentar em torno de 200 pontos durante o quadriênio avaliado. A consecução dos pontos se dá por meio de publicações em periódicos científicos, que são qualificados pela Capes em A1 (100 pontos), A2 (80 pontos), B1 (60 pontos), etc.

Por haver particularidades entre os PPGs, observou-se a partir do gráfico 3 que a pontuação média exigida por parte da coordenação dos Programas aos docentes permanentes variam em proporções aproximadas. No entanto, a maior parte dos docentes que responderam a pesquisa, é cobrada, durante o quadriênio, a apresentarem pelo menos 150 pontos em publicações periódicas. Este valor representa um conceito 3 (regular) e é atribuído para Programas que possuem apenas o curso de mestrado, tendo em vista que para o PPG obter autorização para criação do curso de doutorado, precisa ter no mínimo, conceito 4.

As questões seguintes procuraram investigar o nível de conhecimento dos professores quanto ao processo avaliativo do SNPG, no que concerne às produções docentes, além de como eles reagem, individualmente, com tal sistema de avaliação.

Perguntou-se sobre o nível de conhecimento de cada docente a respeito das qualificações e pontuações atribuídas às revistas científicas: o valor do qualis periódicos.

Conforme apresenta o gráfico 5 , mais de $60 \%$ dos docentes têm bom ou muito conhecimento sobre as pontuações que thes são solicitadas. Contudo, existe um percentual considerável de professores que, ainda que atendendo às exigências 
estabelecidas pelos PPGs, não sabem exatamente como funciona o processo avaliativo da Capes.

Gráfico 5 - Conhecimento sobre pontuação Qualis

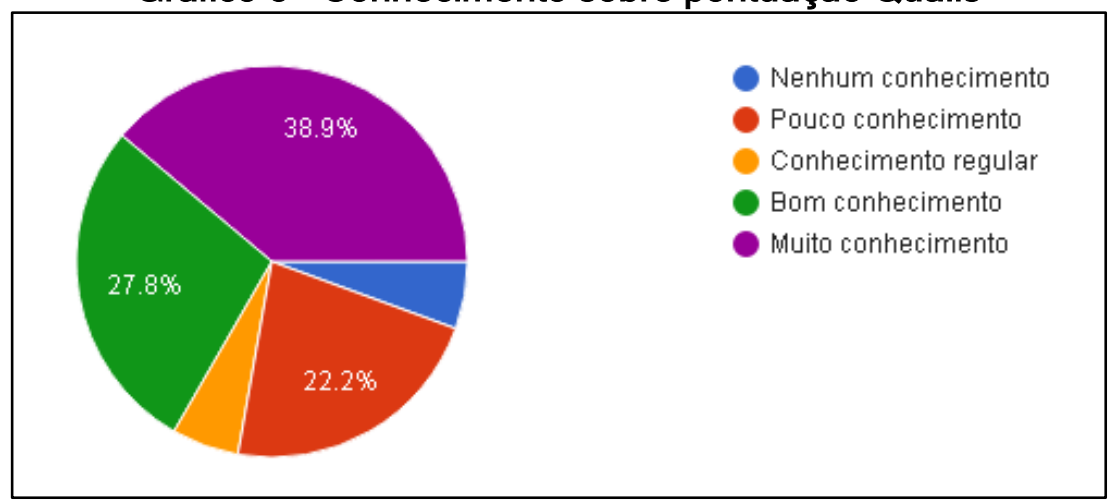

Fonte: Produção da autora.

O gráfico 6 apresenta o ponto de vista dos docentes em relação ao nível de dificuldade encontrada para consecução da pontuação mínima exigida para o quadriênio. Segundo o gráfico, mais de $70 \%$ dos docentes encontram dificuldade, em grau mediano até o grau mais elevado, no alcance da pontuação mínima exigida para a avaliação realizada pela Capes. Um percentual de $55,6 \%$ apresentou resposta em terceiro nível, ou seja, não admite a existência de dificuldade, como também não acha ser uma meta de fácil consecução. A falta de posicionamento poderia sugerir o receio dos docentes em admitirem suas dificuldades em relação à consecução das métricas propostas.

Gráfico 6 - Nível de dificuldade na consecução de métricas 


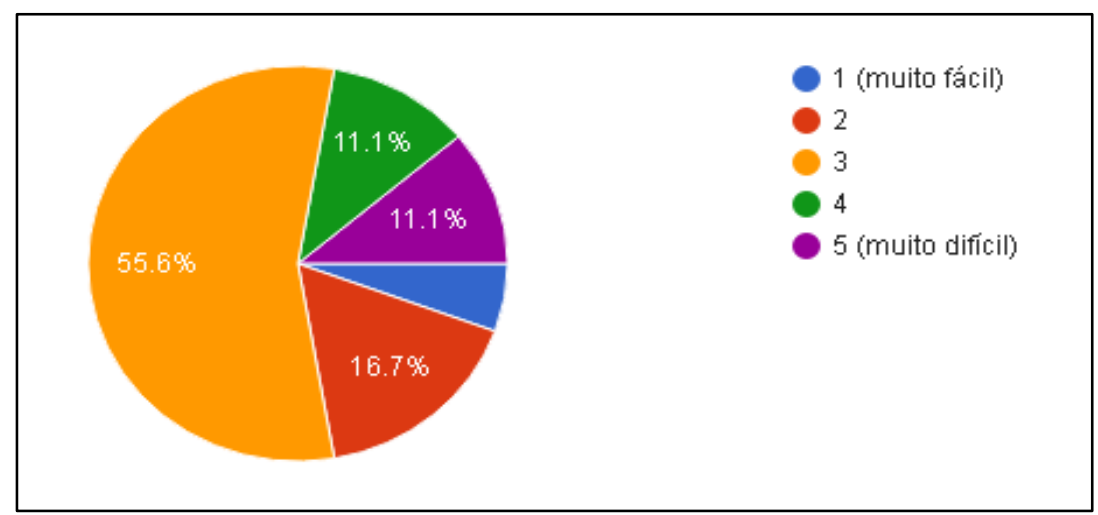

Fonte: Produção da autora.

Questionados sobre em que medida a qualidade da produção acadêmica docente fica contemplada no tipo de processo avaliativo utilizado pelo SNPG, 83,3\% dos professores responderam que nesse sistema a qualidade das publicações está comprometida de maneira razoável, conforme podemos perceber no gráfico 7 .

\section{Gráfico 7 - Nível de qualidade da produção}

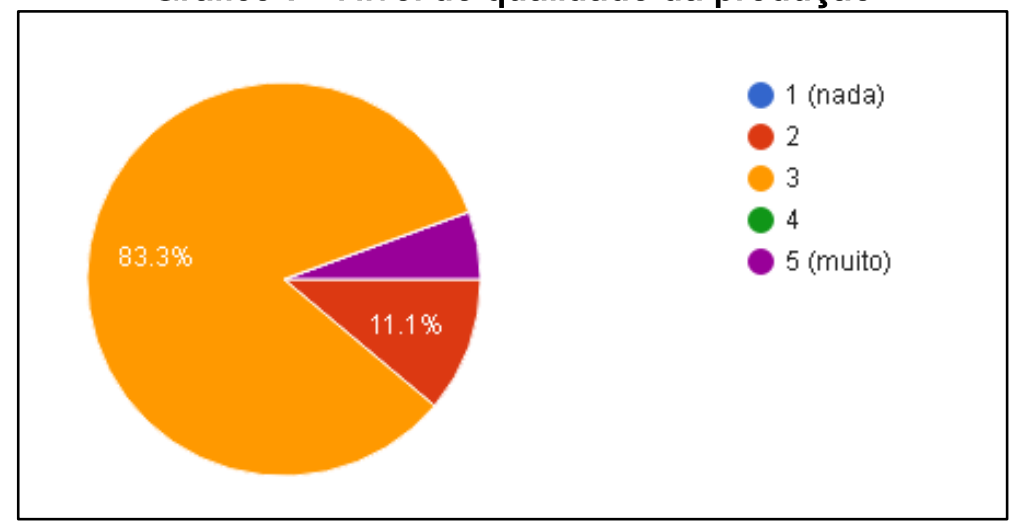

Fonte: Produção da autora.

Assim como ocorreu no gráfico 6 , percebe-se um grande percentual $(83,3 \%)$ de respostas concentradas no nível intermediário (três) de resposta. Em uma pergunta que questiona o nível da qualidade da produção, em que todos os docentes também se incluem, há uma necessidade de autoavaliação por parte desses professores. Acreditase na possibilidade de que haja receio, por parte do docente, em avaliar a própria produção ou do grupo, de maneira negativa. Dessa forma, a melhor opção seria o "meio termo", "nem muito, nem pouco". 
Outra questão que expõe o ponto de vista dos sujeitos da pesquisa indaga em que medida se considera que o processo avaliativo do SNPG pode estimular o plágio ou o autoplágio na produção científica docente, tendo em vista a pressão para publicação existente nesse processo.

Gráfico 8 - Medida de incentivo ao plágio e autoplágio

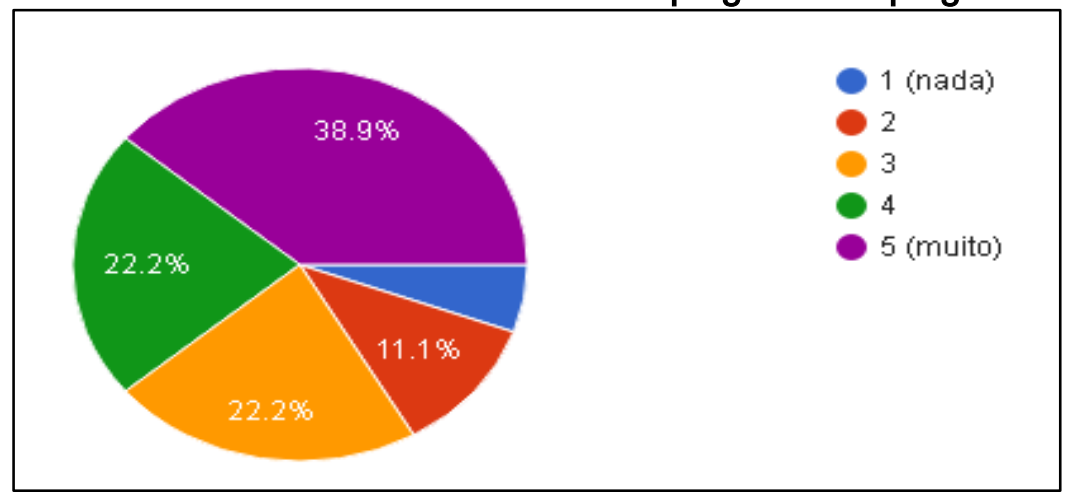

Fonte: Produção da autora.

O gráfico 8 demonstra que mais de $60 \%$ dos respondentes acreditam que o processo avaliativo, na forma em que se estabelece, estimula o plágio e autoplágio nas publicações.

O gráfico 9 apresenta uma síntese das respostas recebidas diante do questionamento sobre a existência de relação de causalidade entre o sistema de avaliação utilizado pela Capes e o crescimento de doenças ocupacionais. Acima de $60 \%$ dos avaliados acreditam que existe relação ou que estão totalmente relacionados o processo avaliativo com as doenças ocupacionais.

Gráfico 9 - Avaliação do SNPG x Doenças ocupacionais

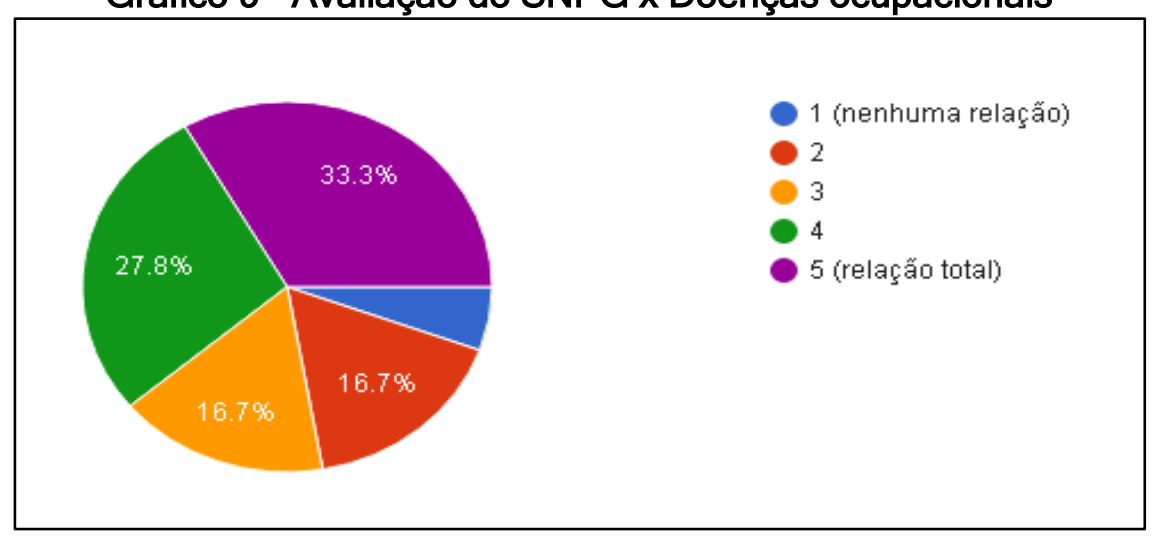

Fonte: Produção da autora. 
O tempo de dedicação do docente para as atividades meio e atividades fim da pesquisa também foi objeto de questionamento. Perguntou-se quanto tempo é dedicado para atividades como preenchimento de SIGAA, Lattes, Sucupira, relatórios, prestação de contas, trâmites para obtenção de recursos, etc (atividades meio), e quanto tempo é dedicado ao desenvolvimento da pesquisa propriamente dita e divulgação dos resultados (atividades fim).

Segundo o que se apresenta no gráfico 10 , mais de $70 \%$ dos docentes comprometem suas atividades de pesquisa propriamente dita, em função das atividades meio, tendo por base o entendimento de que a dedicação do tempo à atividade fim deve ser, no mínimo, superior ao tempo dedicado às atividades meio. Se os docentes dividem igualmente tais atividades ou gastam mais tempo na realização de atividades meio, então se percebe que há comprometimento no tempo dedicado à pesquisa em si.

\section{Gráfico 10 - Tempo de dedicação: atividades meio $x$ atividades fim}

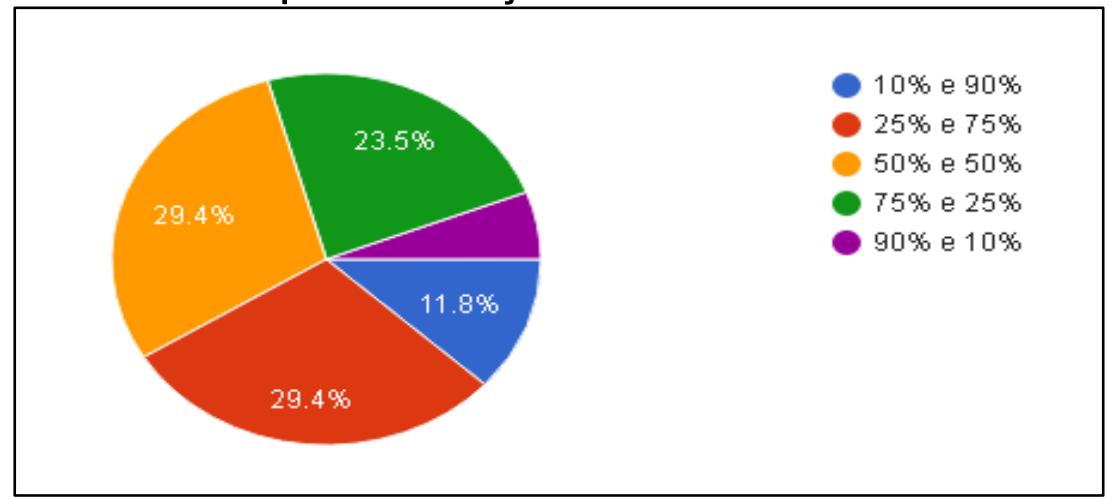

Fonte: Produção da autora.

Por fim, perguntou-se qual a opinião geral dos docentes sobre o processo de avaliação do SNPG, no que se refere à produção científica. Dentre as opções de respostas, conforme podem ser vistas no gráfico 11, 100\% dos entrevistados concordaram que o sistema avaliativo utilizado pela Capes deveria ser reformulado, sendo que $77,8 \%$ acreditam que precisa apenas de alguns ajustes, enquanto que $22,2 \%$ desejam a reformulação total do sistema. 


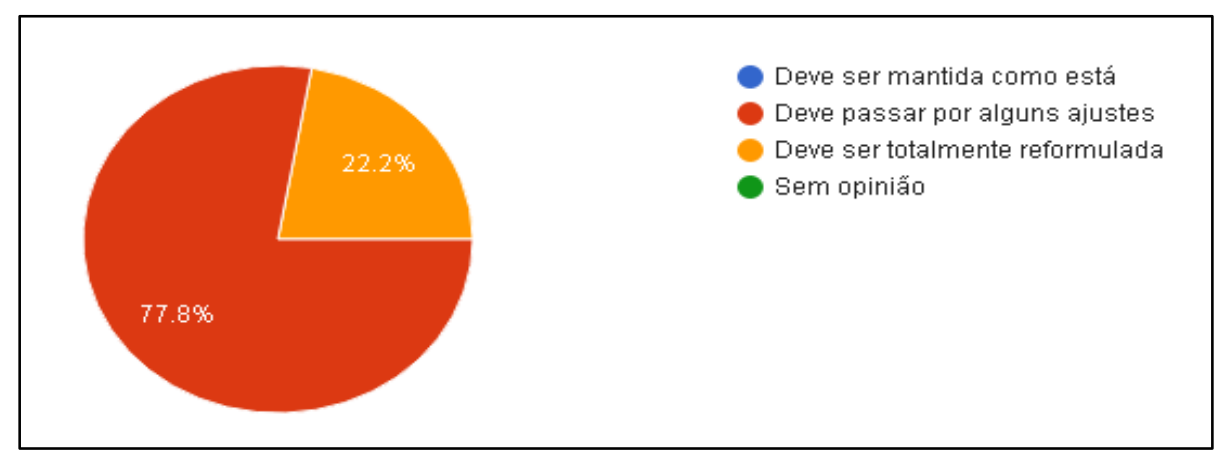

Fonte: Produção da autora.

Outro ponto de questionamento da pesquisa dizia respeito às estratégias utilizadas pelos docentes para atingir as metas solicitadas pelos respectivos PPGs. Algumas das respostas coletadas foram: "seleção de bons alunos; acompanhamento de seus trabalhos de dissertação e tese; envio dos trabalhos para congressos; escolha e submissão de trabalhos para periódicos (do qualis da área)"; "produção conjunta com orientandos"; "publicação de pesquisas desenvolvidas junto aos discentes de iniciação científica, orientandos de graduação e pós-graduação; parcerias interinstitucionais com outros professores"; "produzir 2 artigos por ano e enviar para revistas qualificadas"; "produzir nas férias e em colaboração com alunos ou outros docentes"; "publicar com os alunos em periódicos A1, A2, B1, B2"; "realizar projetos de pesquisa e destes gerar os artigos, e atuação em parceria com docentes de outras IFES"; "estruturação do grupo de pesquisa para atuar em temas emergentes; inserção acadêmica em eventos científicos; estímulo à publicação; comunicação via redes sociais para manter o grupo sempre antenado com as chamadas de revistas e congressos"; "submetendo artigos para vários periódicos".

Ao final do questionário, foram solicitados comentários a respeito do processo avaliativo do SNPG e, quando fosse o caso, sugestões de melhorias ou mudanças. Dentre os comentários realizados, destacaram-se os seguintes: "o processo avaliativo deveria ser mais claro"; "eventuais mudanças deveriam ser para períodos futuros, sem efeitos retroativos"; "a atribuição da categoria qualis para cada periódico não deveria ser feita apenas por um grupo reduzido do comitê da Capes. No longo prazo, a tendência é que o qualis siga as avaliações internacionais (pelo jcr dos periódicos e citações dos artigos) e, portanto, a Capes deveria dirigir esforços para acelerar esta convergência"; "desequilíbrio de exigências entre diferentes áreas"; "deve ser menos quantitativo e mais 
qualitativo"; "o sistema promove a competição desenfreada por pontuação entre os docentes, discentes e entre os programas, o que é nocivo do ponto de vista da saúde mental e física"; "o sistema deve evoluir para medir o fator de impacto da produção da vida do pesquisador e não do quadriênio. Os grandes pesquisadores produzem uma única teoria relevante para a sociedade em toda a sua vida".

Como foi visto, há uma grande insatisfação por parte da maioria dos entrevistados na condução do processo avaliativo do Sistema Nacional de Pós-Graduação, realizado pela Capes. No entanto, em nenhum momento os docentes participantes da pesquisa julgam ser desnecessário o processo avaliativo, apenas discordam da maneira como é conduzido, apresentando as consequências práticas relacionadas à forma de avaliação utilizada atualmente.

\section{CONSIDERAÇÕES FINAIS}

Ao longo dos anos, a universidade se firmou enquanto local prioritário para realização e desenvolvimento de pesquisa científica e tecnológica no país, recebendo apoio financeiro do Estado, por meio de agências de fomento, como CNPq e Capes. Em contrapartida, tais agências se responsabilizaram pela avaliação da produção científica de pesquisadores e programas de pós-graduação, de maneira a destinar auxílios, tais como bolsas de iniciação científica, mestrado, doutorado, pós-doutorado, produtividade, financiamento de projetos de pesquisa, dentre outros.

A Capes, instituição responsável pela realização da avaliação dos programas de pós-graduação, utiliza um sistema avaliativo que dá prioridade a aspectos quantitativos, no que diz respeito às produções acadêmicas docentes, em detrimento de aspectos qualitativos. Esse modo de avaliar as publicações estimula o pesquisador a produzir artigos em um tempo determinado, desconsiderando o tempo real em que sua pesquisa científica finaliza, para que, dessa forma, possa apresentar resultados concretos.

A presente pesquisa, realizada com os docentes permanentes dos PPGs do Centro de Ciências Sociais Aplicadas da UFRN, mostrou a existência de um alto grau de insatisfação com o sistema de avaliação utilizado pela Capes, diante dos problemas que são gerados em decorrência do processo avaliativo. 
Com o retorno da pesquisa de campo, percebeu-se que os motivos da insatisfação com a avaliação utilizada pela Capes decorrem de seu caráter prioritariamente quantitativo. Algumas críticas apontadas pelos docentes participantes da pesquisa a esse sistema avaliativo foram: uniformização das exigências feitas para as diferentes áreas de avaliação; a concentração da responsabilidade pela atribuição das categorias do qualis periódicos; a inexistência de indicadores qualitativos para avaliar a produção científica; padronização "por baixo" da publicação, em nível qualitativo. Foram apontadas, ainda, algumas consequências negativas oriundas desta forma de avaliação, tais como: competição entre docentes, discentes e programas de pós-graduação; possível comprometimento da saúde mental e física do docente; recorrência ao plágio e autoplágio de publicações; comprometimento do desenvolvimento de ciência séria e envolvida com novos descobrimentos.

Além das críticas e consequências apontadas, percebeu-se a existência de um percentual considerável de docentes inseridos nesse processo, que não sabem exatamente como agir diante das exigências da Capes. São levados, muitas vezes pelos coordenadores dos Programas, a publicar em revistas bem qualificadas pelo qualis periódicos, apenas para atingir pontuação suficiente, de forma a mantê-los no PPG. Contudo, não necessariamente conhecem o porquê e como funciona o sistema de avaliação no qual estão inseridos.

Por fim, acredita-se que, embora haja uma discordância entre os docentes de pós-graduação e o método avaliativo utilizado pela Capes para avaliação das produções científicas, é inegável a relevância e necessidade da avaliação para a manutenção e aperfeiçoamento dos programas de pós-graduação. Entretanto, o que os sujeitos da pesquisa explicitaram foi a necessidade de mudanças no sistema avaliativo, para o melhoramento e minimização dos problemas existentes. Enquanto as mudanças não acontecem, os docentes se adaptam ao sistema, encontrando diversos meios para publicar em quantidade e se manter dentro dos padrões exigidos pelos programas.

\section{REFERÊNCIAS}


ALVES, Itala Moreira; MARICATO, João de Melo; MARTINS, Dalton Lopes. Fatores que interferem no (não) credenciamento de pesquisadores em programas de pósgraduação: um estudo nas universidades públicas em Goiás. Em Questão: revista da faculdade de biblioteconomia e comunicação da UFRGS, v. 21, n. 1, p. 150-172, 2015.

BERTOLIN, Júlio C. A transformação do SINAES: da proposta emancipatória à Lei híbrida. Avaliação. Campinas, v. 9, n. 4, p. 67-97, 2004.

BIANCHETTI, Lucídio; VALLE, lone Ribeiro. Produtivismo acadêmico e decorrências às condições de vida/trabalho de pesquisadores brasileiros e europeus. Ensaio: avaliação e políticas públicas em educação, v. 22, n. 82, p. 89-110, 2014.

CAPES. Regulamento para a avaliação trienal 2013 (2010-2012). Brasília, 2013.

Disponível em: <http://www.avaliacaotrienal2013.capes.gov.br/home-page/regulamentoda-trienal>. Acesso em: 21 nov. 2016.

CAPES. Sobre a Avaliação. Brasília, 2014. Disponível em:

<http://www.capes.gov.br/avaliacao/sobre-a-avaliacao>. Acesso em: 21 nov. 2016.

HORTA, José Silvério Baia. Avaliação da pós-graduação: com a palavra os coordenadores de Programas. Perspectiva, v. 24, n. 1, p. 19-47, 2006.

LAKATOS, E. M.; MARCONI, M. A. Fundamentos de Metodologia Científica. 5. ed. São Paulo: Atlas, 2003.

MOREIRA, M. L.; VELHO, L. Pós-graduação no Brasil: da concepção "ofertista linear" para "novos modos de produção do conhecimento": implicações para avaliação.

Avaliação, Campinas/Sorocaba, v. 13, n. 3, p. 625-45, nov. 2008.

RAMPAZZO, Lino. Metodologia científica para alunos dos cursos de graduação e pósgraduação. São Paulo: Edições Loyola, 2002.

SEVERINO, Antônio Joaquim. Metodologia do trabalho científico. 23. ed. rev. e atual. São Paulo: Cortez, 2007.

SOUZA, Renato Santos de. A doença da "normalidade" na universidade. In:

NASCIMENTO, L.F.M. (Org.) Lia, mas não escrevia (livro eletrônico): contos, crônicas e poesias. Porto Alegre: LFM do Nascimento, 2014. Disponível em: <

http://www.pragmatismopolitico.com.br/2014/07/a-doenca-da-normalidade-nauniversidade.html>. Acesso em: 21 nov. 2016. 